\title{
Unilateral electronegative ERG in a presumed central retinal artery occlusion
}

This article was published in the following Dove Press journal:

Clinical Ophthalmology

16 November 2010

Number of times this article has been viewed

\author{
Luiz H Lima' \\ Wener Cella ${ }^{2,4}$ \\ Claudia Brue ${ }^{5}$ \\ Stephen H Tsang 2.3 \\ 'Federal University of Sao Paulo \\ (UNIFESP), Sao Paulo, Brazil; \\ ${ }^{2}$ Department of Ophthalmology, \\ ${ }^{3}$ Bernard and Shirlee Brown Glaucoma \\ Laboratory, Edward S Harkness \\ Eye Institute and Departments of \\ Opthamology, Pathology and Cell \\ Biology, Columbia University, New \\ York, NY, USA; ' ${ }^{4}$ Department of \\ Ophthalmology, University of Brasilia, \\ Brasilia, Brazil; ${ }^{5}$ Department of \\ Opthamology, University Politecnica \\ delle Marche, Ancona, Italy
}

\begin{abstract}
A unilateral electronegative electroretinogram (ERG) was seen in a 94-year-old man with presumed central retinal artery occlusion. Goldmann perimetry revealed central scotoma in the right eye and no abnormalities in the left eye. Full-field ERG in the right eye described a reduction of the b-wave with a relative preservation of the a-wave which is characteristic of electronegative ERG. Hence, our case illustrates that ERG testing is essential for the work-up of individuals with suspected retinal vascular disorders.
\end{abstract}

Keywords: central retinal artery occlusion, electronegative ERG, inner retina, spectral domain optical coherence tomography

\section{Introduction}

Patients with acute central retinal artery occlusion (CRAO) typically relate a history of painless visual loss occurring over several seconds followed by classic signs of retinal infarction in the fundus. Spontaneous recanalization frequently occurs in many patients making CRAO a challenging diagnosis. ${ }^{1}$ In such cases, electroretinogram (ERG) can be a helpful ancillary test for CRAO diagnosis. As the retinal artery supplies the middle and inner layers of the retina, the physiological consequence of CRAO is a predominant reduction of the scotopic maximal ERG b-wave with preservation of the a-wave. ${ }^{2}$ A negative full-field ERG usually describes International Standard for Clinical Electrophysiology of Vision standard maximal response in which the amplitude of b-wave is smaller than the minimally attenuated a-wave..$^{3-5}$ This reduced $b$-wave is usually associated with a number of congenital and acquired conditions such as X-linked juvenile retinoschisis, ${ }^{6,7}$ congenital stationary night blindness, ${ }^{8,9} \mathrm{CRAO},{ }^{10,11}$ birdshot chorioretinopathy, ${ }^{12-14}$ paraneoplastic and autoimmune retinopathies, ${ }^{15-17}$ and retinal toxicity. ${ }^{18,19}$

We report an atypical presentation of CRAO in which a unilateral negative ERG was valuable in diagnosis and the initiation of systemic work-up.

\section{Case report}

A 94-year-old ophthalmologist noted central vision deterioration in the right eye over the past two years. Medical history was significant for an 18-year history of systemic hypertension, for which the patient was being treated with beta-blocker (atenolol) and diuretic (hydrochlorotiazide) drugs. Screening procedures for malignancy including a careful medical history, a chest X-ray, and liver enzymes were negative. There was neither history of retinotoxic medication use, nor family history of eye disease. Ultrasound examination of the carotid arteries was performed and showed tiny atherosclerotic plaque
Bernard and Shirlee Laboratory, Edward S Harkness Eye Institute, Columbia University, 160 Fort Washington Avenue, Room 513 , New York, NY 10032, USA

$\mathrm{Tel}+\mathrm{I} 212342$ I I86

Fax + I 2123427942

Email gene.targeting@gmail.com 
without hemodynamically compromised lesion. Two years before his presentation, his ophthalmologist recorded 20/60 vision in the right eye and 20/20 in the left eye.

Visual acuity at presentation was 20/80 in the right eye and $20 / 20$ in the left eye. The patient's central vision in the right eye progressively deteriorated but stabilized over six months, resulting in acuity of 20/100. Anterior segment examination was unremarkable, except for mild superficial punctate keratitis, a few guttata, more prominently on the left cornea, and pseudophakia. There was no iris neovascularization in both eyes. The funduscopic examination revealed hard drusen on the macular area in both eyes, and atrophic retinal pigment epithelium (RPE) changes with pigmentary clumps on the macular area of left eye. Minor retinal artery narrowing was observed in both eyes without optic atrophy (Figure 1A and 1B). Fundus fluorescein angiography (FA) was unremarkable in the right eye and revealed transmission defect in the posterior pole compatible with RPE abnormalities in the left eye (Figure 1C and 1D). FA choroidal phase was 6 seconds in the right eye and 5 seconds in the left eye; FA arteriovenous phase was 14 seconds in the right eye and 11 seconds in the left eye. Spectral domain optical coherence tomography (SD-OCT) demonstrated reduced thickness of the inner retina in both eyes but more prominently in the right eye (Figure 2). The thickness of the inner retina (from retinal nerve fiber layer to inner nuclear layer) was measured $600 \mu \mathrm{m}, 1,000 \mu \mathrm{m}$, and 2,000 $\mu \mathrm{m}$ nasally and temporally from the fovea. We also measured the inner retina

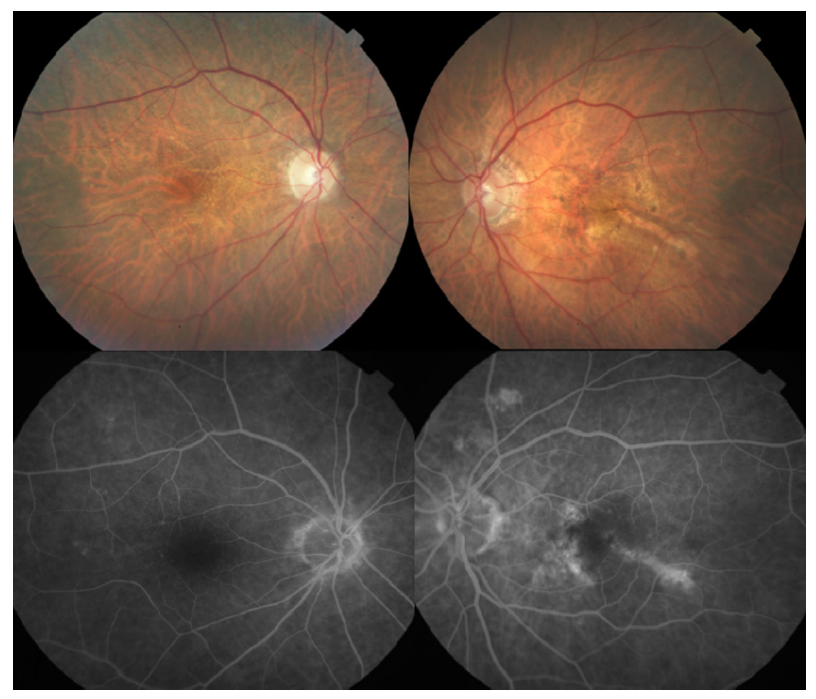

Figure I Color fundus photographs shows few drusen on the posterior pole in both eyes, and retinal pigment epithelium (RPE) atrophy with pigmentary clumps on the macular area of left eye. Minimal retinal artery narrowing can be observed in both eyes. Fundus fluorescein angiography depicts window defect in the posterior pole compatible with RPE atrophy in the left eye in the venous phase. There was no apparent delayed fluorescein filling in both eyes.

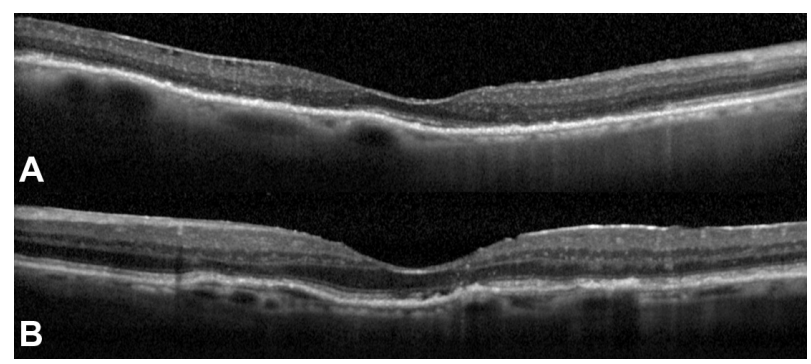

Figure 2 Spectral domain optical coherence tomography (SD-OCT) revealed reduced retinal thickness in the right eye $(\mathbf{A})$ and left eye $(\mathbf{B})$. Note the decreased thickness of the inner retina in right eye is more advanced than the left eye.

thickness at the same locations described previously in 10 normal age-matched control eyes. The measurements were performed using the 1,000 $\mu \mathrm{m}$ caliper available in the OCTSLO Spectralis, Heidelberg Retina Angiograph 2 (Heidelberg Engineering, Dossenheim, Germany). Our measurements showed that the inner retina thicknesses were decreased at $600 \mu \mathrm{m}, 1,000 \mu \mathrm{m}$, and 2,000 $\mu \mathrm{m}$ nasally and temporally from the fovea in the patient's right eye in comparison to the left eye and normal control eyes (Figure 3). Goldmann perimetry demonstrated central scotoma in the right eye and no abnormalities in the left eye. Full-field ERG in the right eye was attenuated in both scotopic and photopic responses and revealed a b-wave smaller than the a-wave amplitude, ie, electronegative maximal response. In the left eye, minimal scotopic and photopic attenuation was observed (Figure 4). Western blot analysis of 1:500 dilutions of the patient's serum did not show any reactivity against retinal protein extract.

\section{Discussion}

Our patient presented with a history of systemic hypertension treated with antihypertensive medications and vision loss of

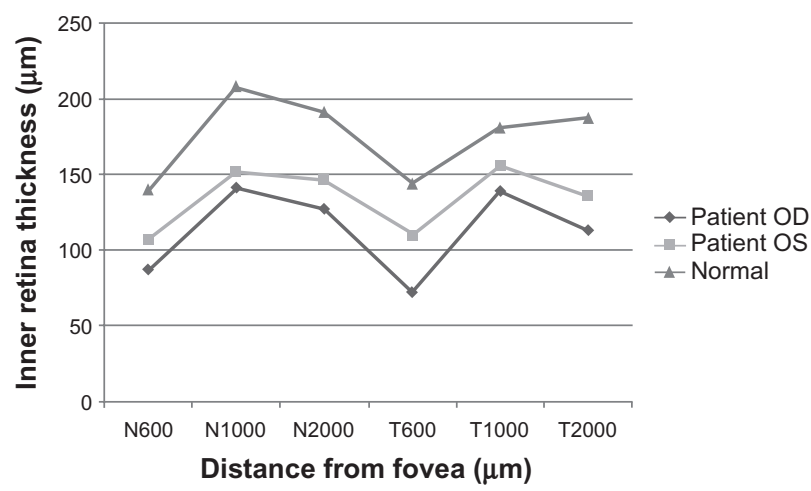

Figure 3 The thickness of the inner retina was established as the distance between retinal nerve fiber layer and inner nuclear layer and was measured using the I,000 $\mu \mathrm{m}$ caliper available in the OCT-SLO Spectralis. Ten age-matched normal eyes were used as controls. Observe the decrease in the nasal and temporal inner retinal thickness in the right eye in comparison to the left and normal control eyes. 


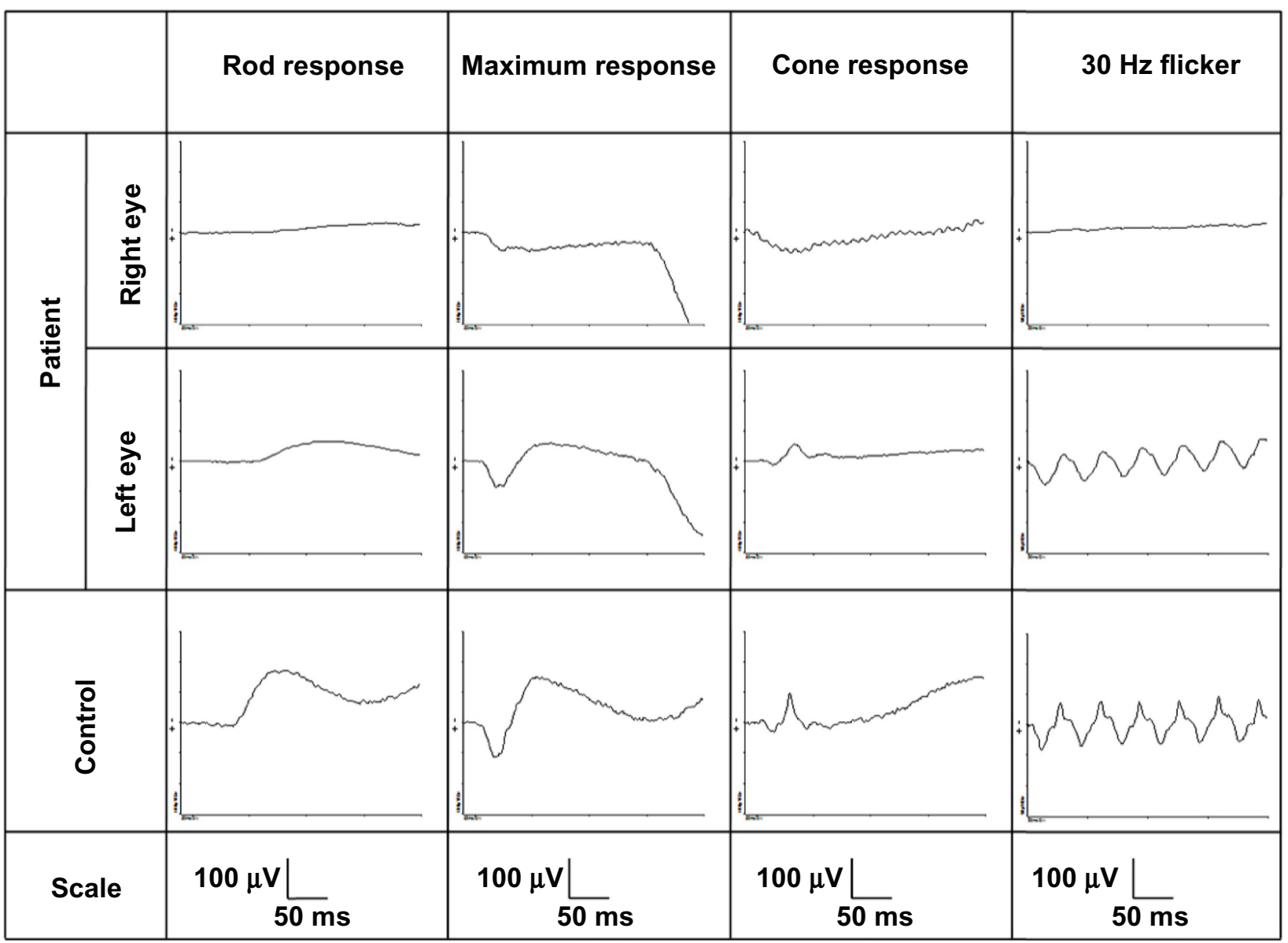

Figure 4 Full-field electroretinogram (ERG) showing electronegative ERG in the right eye and minimal generalized dysfunction in the left eye. Scotopic rod specific ERG has b-wave amplitude of $27 \mu \mathrm{V}$ and in the right and $7 \mathrm{I} \mu \mathrm{V}$ in the left. Maximal ERG a- and b-wave amplitudes were 59 and $9 \mu \mathrm{V}$ in the right eye and 83 and I $30 \mu \mathrm{V}$ in the left eye. Maximal ERG a-wave implicit times were 22 milliseconds in the right and 19 milliseconds in the left. Transient photopic ERG b-wave amplitudes were extinguished in the right and $68 \mu \mathrm{V}$ in the left. Photopic $30 \mathrm{~Hz}$ flicker ERG were extinguished in the right but had implicit times and amplitudes of $50 \mu \mathrm{V}$ and 30 milliseconds in the left.

unknown origin with minimal abnormalities in the clinical and imaging studies. The ERG revealed a unilateral negative waveform. Based on his history, imaging examinations, and on the ERG result, CRAO and autoimmune retinopathies were considered as differential diagnosis. Although autoimmune retinopathies, including cancer-associated retinopathy and melanoma-associated retinopathy, can cause electronegative ERG, they are bilateral. Indeed, autoimmune retinopathy patients tend to have antiretinal antibody activity often with different antibodies found on immunoblots. ${ }^{20-22}$ The findings of generalized vascular narrowing, even though minimal, lack any sign of acute ischemia and the unilateral electronegative maximal ERG in the right eye were consistent with inner retinal dysfunction due to an old central arteriolar occlusion in the right eye. A reduction of the b-wave with a relative preservation of the a-wave of the scotopic maximal ERG is a characteristic of eyes with CRAO. ${ }^{2,5}$ In addition, the reduced inner retina thickness more prominent in the right eye than in the left eye demonstrable by SD-OCT measurements strengthens the diagnosis of CRAO since CRAO is classically associated with a reduced thickness in the inner retinal layers. ${ }^{23,24}$

Although the classic retinal findings of CRAO have been described, a high degree of suspicion is needed to diagnose CRAO in some cases because of transitory abnormalities in the fundus appearance, FA findings for CRAO, the insensitivity of carotid Doppler imaging and echocardiography for associated lesions, and the subtlety of residual findings after CRAO. In such cases, mainly represented by the transient type, the diagnosis of CRAO is intricate and an electronegative ERG can support the diagnosis of artery occlusion. ${ }^{1,2}$ CRAO is reported to be the most common cause of a unilateral negative ERG. ${ }^{25}$

We report an atypical case of CRAO without its characteristic angiographic findings, except mild retinal artery narrowing detected on his fundus and imaging exams, in which ERG was essential for diagnosis. Our case, therefore, illustrates that ERG testing is helpful for the work-up of individuals with suspected retinal vascular disorders. 


\section{Disclosure}

The authors report no conflicts of interest in this work. NIH Grant R01EY018213 (SHT), unrestricted funds from Research to Prevent Blindness, New York, NY, the Foundation Fighting Blindness, Schneeweiss Stargardt Fund, and The Starr Foundation. SHT is a fellow of the BurroughsWellcome Program in Biomedical Sciences and has been supported by the Bernard Becker-Association of University Professors in Ophthalmology Research to Prevent Blindness Award and Foundation Fighting Blindness, Dennis W Jahnigen Award of the American Geriatrics Society, Crowley Family Fund, Joel Hoffman Fund, Gale and Richard Siegel Stem Cell Fund, Charles Culpeper Scholarship, Schneeweiss Stem Cell Fund, Irma T Hirschl Charitable Trust, Bernard and Anne Spitzer Stem Cell Fund, Barbara and Donald Jonas Family Fund, Eye Surgery Fund, and Professor Gertrude Rothschild Stem Cell Foundation.

\section{References}

1. Hayreh SS, Zimmerman MB. Fundus changes in central retinal artery occlusion. Retina. 2007;27(3):276-289.

2. Karpe G, Ucherman A. The clinical electroretinogram. VII. The electroretinogram in circulatory disturbances of the retina. Acta Ophthalmol (Copenh). 1955;33(5):493-516.

3. Fishman GA, Birch DG, Holder GE, Brigell MG. Electrophysiologic Testing in Disorders of the Retina, Optic Nerve and Visual Pathway. 2nd ed. New York, NY: Oxford University Press; 2001.

4. Heckinlively JR, Arden GB, editors. Principles and Practice of Clinical Electrophysiology of Vision. St Louis, MO: Mosby; 1991.

5. Koh AH, Hogg CR, Holder GE. The incidence of negative ERG in clinical practice. Doc Ophthalmol. 2001;102(1):19-30.

6. Kellner U, Brummer S, Foerster MH, Wessing A. X-linked congenital retinoschisis. Graefes Arch Clin Exp Ophthalmol. 1990;228(5): 432-437.

7. Bradshaw K, George N, Moore A, Trump D. Mutations of the XLRS1 gene cause abnormalities of photoreceptor as well as inner retinal responses of the ERG. Doc Ophthalmol. 1999;98(2):153-173.

8. Miyake Y, Yagasaki K, Horiguchi M, Kawase Y, Kanda T. Congenital stationary night blindness with negative electroretinogram. Arch Ophthalmol. 1986;104(7):1013-1020.

9. Noble KG, Carr RE, Siegel IM. Autosomal dominant congenital stationary night blindness and normal fundus with an electronegative electroretinogram. Am J Ophthalmol. 1990;109(5):44-48.
10. Henkes HE. Electroretinography in circulatory disturbances of the retina. II. The electroretinogram in cases of occlusion of the central retinal artery or one of its branches. AMA Arch Ophthalmol. 1954;51(1): $42-53$.

11. Yotsukura J, Adach-Usami E. Correlation of electroretinographic changes with visual prognosis in central retinal artery occlusion. Ophthalmologica. 1993;207(1):13-18.

12. Priem HA, de Rouck, de Laey J, Bird AC. Electrophysiologic studies in birdshot chorioretinopathy. Am J Ophthalmol. 1988;106(4):430-436.

13. Hirose T, Katsumi O, Pruett RC, Sakaue H, Mehta M. Retinal function in birdshot retinochoroidopathy. Acta Ophthalmol (Copenh). 1991;69(3): 327-337.

14. Holder GE, Robson AG, Pavesio C, Graham EM. Electrophysiological characterization and monitoring in the management of birdshot chorioretinopathy. Br J Ophthalmol. 2005;89:709-718.

15. Weleber RG, Watzke RC, Shults WT, et al. Clinical and electrophysiologic characterization of paraneoplastic and autoimmune retinopathies associated with enolase autoantibodies. Am J Ophthalmol. 2005;139(5):780-794.

16. Berson EL, Lessell S. Paraneoplastic night blindness with malignant melanoma. Am J Ophthalmol. 1988;106(3):307-311.

17. Alexander KR, Fishman GA, Peachey NS, Marchese AL, Tso MO. 'On' response defect in paraneoplastic night blindness with cutaneous malignant melanoma. Invest Ophthalmol Vis Sci. 1992;33(3):477-483.

18. Bacon P, Spalton DJ, Smith SE. Blindness from quinine toxicity. $\mathrm{Br} J$ Ophthalmol. 1988;72(3):219-224.

19. Treichel JL, Murray TG, Lewandowski MF, Stueven HA, Eells JT, Burke JM. Retinal toxicity in methanol poisoning. Retina. 2004;24(2): 309-312.

20. Adamus G, Aptsiauri N, Guy J, Heckenlively J, Flannery J, Hargrave PA. The occurrence of serum autoantibodies against enolase in cancerassociated retinopathy. Clin Immunol Immunopathol. 1996;78(2): 120-129.

21. Thirkill CE, FitzGerald P, Sergott RC, Roth AM, Tyler NK, Keltner JL. Cancer-associated retinopathy (CAR syndrome) with antibodies reacting with retinal, optic-nerve, and cancer cells. $N$ Engl J Med. 1989; 321(23):1589-1594.

22. Adamus G. Autoantibody-induced apoptosis as a possible mechanism of autoimmune retinopathy. Autoimmun Rev. 2003;2(2):63-69.

23. Shinoda K, Yamada K, Matsumoto CS, Kimoto K, Nakatsuka K. Changes in retinal thickness are correlated with alterations of electroretinography in eyes with central retinal artery occlusion. Graefes Arch Clin Exp Ophthalmol. 2008;246(7):949-954.

24. Falkenberry SM, Ip MS, Blodi BA, Gunther JB. Optical coherence tomography findings in central artery occlusion. Ophthalmic Surg Lasers Imaging. 2006;37(6):502-505.

25. Robson AG, Richardson EC, Koh AH, et al. Unilateral electronegative ERG of non-vascular etiology. Br J Ophthalmol. 2005;89(12): $1620-1626$.
Clinical Ophthalmology

\section{Publish your work in this journal}

Clinical Ophthalmology is an international, peer-reviewed journal covering all subspecialties within ophthalmology. Key topics include: Optometry; Visual science; Pharmacology and drug therapy in eye diseases; Basic Sciences; Primary and Secondary eye care; Patient Safety and Quality of Care Improvements. This journal is indexed on Submit your manuscript here: http://www.dovepress.com/clinical-ophthalmology-journal

\section{Dovepress}

PubMed Central and CAS, and is the official journal of The Society of Clinical Ophthalmology (SCO). The manuscript management system is completely online and includes a very quick and fair peer-review system, which is all easy to use. Visit http://www.dovepress.com/ testimonials.php to read real quotes from published authors. 